\title{
Theoretical Estimation of Energy Balance Components in Water Networks for Top-Down Approach
}

\author{
Surachai Lipiwattanakarn, Suparak Kaewsang, Natchapol Charuwimolkul, Jiramate Changklom and \\ Adichai Pornprommin *(D)
}

Citation: Lipiwattanakarn, S.; Kaewsang, S.; Charuwimolkul, N.; Changklom, J.; Pornprommin, A. Theoretical Estimation of Energy Balance Components in Water Networks for Top-Down Approach. Water 2021, 13, 1011. https:// doi.org/10.3390/w13081011

Received: 19 February 2021

Accepted: 6 April 2021

Published: 7 April 202

Publisher's Note: MDPI stays neutral with regard to jurisdictional claims in published maps and institutional affiliations.

Copyright: (c) 2021 by the authors. Licensee MDPI, Basel, Switzerland. This article is an open access article distributed under the terms and conditions of the Creative Commons Attribution (CC BY) license (https:// creativecommons.org/licenses/by/ $4.0 /)$.
Department of Water Resources Engineering, Faculty of Engineering, Kasetsart University, Bangkok 10900, Thailand; fengsuli@ku.ac.th (S.L.); suaparak.k@ku.th (S.K.); natchapol.ch@ku.th (N.C.); jiramate.ch@ku.th (J.C.)

* Correspondence: fengacp@ku.ac.th

\begin{abstract}
The energy balance calculation for pressurized water networks is an important step in assessing the energy efficiency of water distribution systems. However, the calculation generally requires mathematical modelling of the water networks to estimate three important energy components: outgoing energy through water loss $\left(E_{l}\right)$, friction energy loss $\left(E_{f}\right)$ and energy associated with water loss $\left(E_{W L}\right)$. Based on a theoretical energy balance analysis of simplified pipe networks, a simple method is proposed to estimate $E_{l}, E_{f}$ and $E_{W L}$ with minimum data requirements: input energy, water loss $(W L)$ and head loss between the source and the minimum energy point $(\Delta H)$. By inclusion of the head loss in water networks into the estimation, the percentages of $E_{l}$ and $E_{W L}$ are lower and higher, respectively, than using only the percentage of $W L$. The percentage of $E_{f}$ can be a function of the percentage of $\Delta H$. By demonstrating our analysis with the simulation results from the mathematical models of 20 real water networks, the proposed method can be used to effectively estimate $E_{l}, E_{f}$ and $E_{W L}$ as a top-down energy balance approach.
\end{abstract}

Keywords: energy balance; friction; water loss; pressurized water networks; theoretical estimation

\section{Introduction}

The demand for energy is intensifying in the water sector. The International Energy Agency (IEA) [1] estimated that $4 \%$ of total global electricity was consumed by the water sector in 2014 and it may rise by $80 \%$ by 2040. In Portugal, urban water and wastewater systems use $3 \%-4 \%$ of the total national electricity [2]. In Brazil, over $1.9 \%$ of total electricity energy is consumed by water supply systems [3]. Pelli and Hitz [4] estimated that supplying drinking water and industrial water worldwide can consume as much as $2 \%-10 \%$ of a country's total electricity usage. The World Bank [5] reported that electricity costs are $5 \%-30 \%$ of the total operating cost of water and wastewater utilities worldwide. In Latin America and the Caribbean, energy is generally $30 \%-40 \%$ of the operational costs of water supply services [6]. Nevertheless, IEA [1] suggested that there is a great opportunity to save energy in the water sector by $15 \%$ by 2040 if economically available energy efficiency and energy recovery potentials are exploited. Achieving this will require accurate and comprehensive energy assessment in the water sector.

In the past, energy assessment in water supply systems was focused on pump inefficiency. Later, the interest extended to assess the energy losses due to friction and leakage in water networks [4,7,8]. Bylka and Mroz [9] reviewed energy assessment methods for water supply systems and categorized them into two groups. While the first group is based solely on data collected in water utilities, the second one is based on both the data and modelling of physical processes. Thus, more detailed results from the second group can support a strategy for increasing the energy efficiency of each process. Since mathematical modelling requires collecting a large amount of data and is time consuming to analyze, it is usually applied on a relatively small network. Cabrera et al. [10] presented one of the first energy audit methods for water networks based on the modelling of physical processes. Over the 
past decade, more complex and comprehensive methods have been developed for energy balance and assessment based on physical processes to evaluate energy transformation and efficiency in water supply systems [11-22]. In addition, there are successful energy assessments of real networks based on physical processes in many countries [19-27].

Figure 1 shows two simplified versions of energy balances in water networks considering only leakage (as water loss) and pipe friction proposed by Cabrera et al. [10] and Mamade et al. [19-21]. The energy balance in Cabrera et al. [10] (Figure 1a) shows the input energy $\left(E_{i n}\right)$ divided into three components: the energy delivered to users $\left(E_{u}\right)$, the outgoing energy through water loss $\left(E_{l}\right)$ and the friction energy loss $\left(E_{f}\right)$. To be consistent with the International Water Association (IWA) water balance [28], on the other hand, Mamade et al. [19-21] divided $E_{\text {in }}$ into two components: the energy associated with authorized consumption $\left(E_{A C}\right)$ and the energy associated with water loss $\left(E_{W L}\right)$, as shown in Figure $1 \mathrm{~b}$. Theoretically, these components should be calculated through mathematical models, which are based on physical processes. For the balance in Cabrera et al. [10], a calibrated mathematical model is sufficient to evaluate $E_{u}, E_{l}$ and $E_{f}$. However, for the balance in Mamade et al. [19-21], an additional model without water loss is needed to estimate the friction energy loss for a water loss-free network $\left(E_{f o}\right)$. Mamade et al. [21] proposed the top-down and bottom-up approaches for their energy balance. In the top-down approach, the ratio between $E_{W L}$ and $E_{i n}$ is assumed to be the ratio between water loss $(W L)$ and system input volume (SIV). To prove the assumption, the comparison between $E_{W L} / E_{\text {in }}$ and $W L / S I V$ was carried out through simulation using the mathematical models of real networks. The linear trendline shows that the value $E_{W L} / E_{i n}$ is slightly higher than $W L / S I V$. In this study, the evaluation of $E_{W L} / E_{i n}$ is reanalyzed by using both theoretical analysis and mathematical models and the estimations of $E_{l} / E_{i n}$ and $E_{f} / E_{i n}$ are also investigated. In Section 2, the theoretical analysis of energy balance describes the behaviors of each energy balance component and establishes the basic relationships between each variable. In Section 3, the mathematical models of 20 real district metering area (DMA) networks are introduced, and the relationships between the model results and basic parameters are investigated. Section 4 combines the results from the theory and the models, and the coefficient in the theory is calibrated using the model simulation results. The accuracy of the estimation of $E_{l}, E_{f}$ and $E_{W L}$ is evaluated in order to apply as the top-down energy balance approach. Finally, the conclusion is provided in Section 5 .

\begin{tabular}{|c|c|}
\hline \multirow{4}{*}{$\begin{array}{c}\text { Input energy } \\
\left(E_{\text {in }}\right)\end{array}$} & $\begin{array}{c}\text { Energy delivered to users } \\
\left(E_{u}\right)\end{array}$ \\
\cline { 2 - 2 } & $\begin{array}{c}\text { Outgoing energy through water loss } \\
\left(E_{l}\right)\end{array}$ \\
\cline { 2 - 2 } & Friction energy loss \\
$\left(E_{f}\right)$
\end{tabular}

(a)

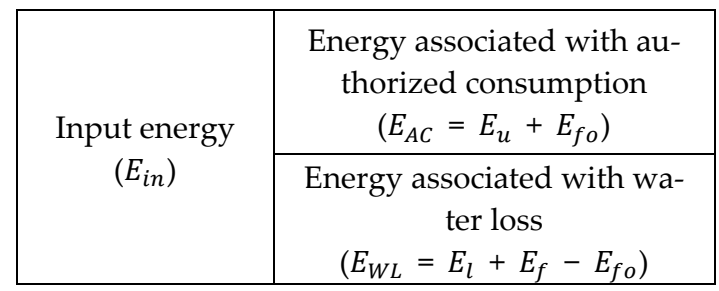

(b)

Figure 1. Two simplified energy balance concepts in water networks considering only leakage (as water loss) and pipe friction, where (a) is proposed by Cabrera et al. [10] and (b) is proposed by Mamade et al. [19-21].

\section{Theoretical Analysis of Energy Balance}

In this section, the energy balance principle is introduced and analyzed theoretically on two simple pressurized water networks. The energy balance components are calculated and then normalized to the non-dimensional version. They are used for the top-down energy balance estimation. 


\subsection{Single Pipe Network}

As the first case, Figure 2 shows a single pipe network consisting of a source and a demand node at the pipe end. The input energy head is defined as $H$, and the system inflow is $Q$. Using the water balance concept, $Q$ can be divided into

$$
Q=Q_{u}+Q_{l}
$$

where $Q_{u}$ is the flow to supply authorized consumption and $Q_{l}$ is the flow due to water loss.

Then, we introduce the ratio of water loss $(p)$ as

$$
p=\frac{Q_{l}}{Q}
$$

At the demand node at the pipe end, $Q$ is out of the network and thus, the friction head loss along the pipe $(\Delta H)$ can be expressed as

$$
\Delta H=K Q^{n}
$$

where $K$ is the loss coefficient and $n$ is the flow exponent.

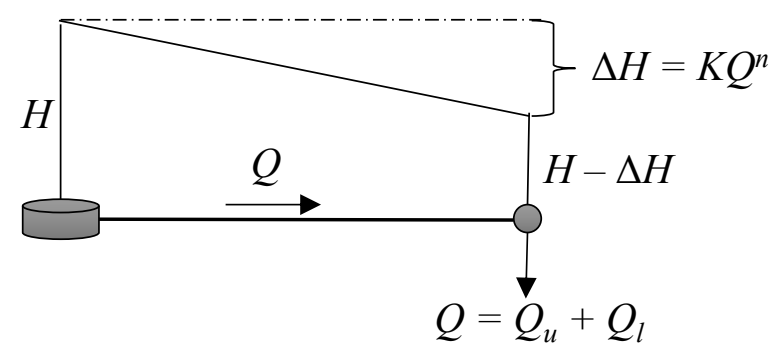

Figure 2. Energy balance for single pipe network.

According to the energy balance concepts in Figure 1, the energy balance components can be calculated as

1. Input energy $\left(E_{\text {in }}\right)$

$$
E_{\text {in }}=\gamma Q H
$$

2. Outgoing energy through water loss $\left(E_{l}\right)$

$$
E_{l}=\gamma Q_{l}\left(H-K Q^{n}\right)
$$

3. Friction energy loss $\left(E_{f}\right)$

$$
E_{f}=\gamma Q\left(K Q^{n}\right)
$$

4. Friction energy loss for a water loss-free network $\left(E_{f_{o}}\right)$

$$
E_{f o}=\gamma Q_{u}\left(K Q_{u}^{n}\right)
$$

5. Energy associated with water loss $\left(E_{W L}\right)$

$$
E_{W L}=E_{l}+E_{f}-E_{f o}
$$

where $\gamma$ is specific weight of water. 
The nondimensionalization is introduced here. According to Mamade et al. [21], $E_{W L}$ divided by $E_{\text {in }}$ can be approximated by $p$. Therefore, the energy balance components in Equations (4)-(8) are normalized by $E_{i n}$ as

$$
\left(E_{i n}^{\prime}, E_{l}^{\prime}, E_{f}^{\prime}, E_{f_{o}}^{\prime}, E_{W L}^{\prime}\right)=\frac{\left(E_{i n}, E_{l}, E_{f}, E_{f o}, E_{W L}\right)}{E_{i n}}
$$

and $\Delta H$ is normalized by $H$ as

$$
\Delta H^{\prime}=\frac{K Q^{n}}{H}=\frac{\Delta H}{H}
$$

where the variables with superscript ' are the normalized versions of the variables.

Thus, the normalized energy balance components for the first case in Figure 2 can be written as

1. Normalized input energy $\left(E_{i n}^{\prime}\right)$

$$
E_{\text {in }}^{\prime}=1
$$

2. Normalized outgoing energy through water loss $\left(E_{l}^{\prime}\right)$

$$
E_{l}^{\prime}=\left(\frac{Q_{l}}{Q}\right)\left(\frac{H-K Q^{n}}{H}\right)=p-p \Delta H^{\prime}
$$

3. Normalized friction energy loss $\left(E_{f}^{\prime}\right)$

$$
E_{f}^{\prime}=\Delta H^{\prime}
$$

4. Normalized friction energy loss for a water loss-free network $\left(E_{f o}^{\prime}\right)$

$$
E_{f o}^{\prime}=\left(\frac{Q_{u}}{Q}\right)\left(\frac{K Q_{u}^{n}}{H}\right)=(1-p)^{n+1} \Delta H^{\prime}
$$

5. Normalized energy associated with water loss $\left(E_{W L}^{\prime}\right)$

$$
E_{W L}^{\prime}=p+p_{n} \Delta H^{\prime}
$$

where

$$
p_{n}=(1-p)\left[1-(1-p)^{n}\right]
$$

The energy components relating to water loss, $E_{l}^{\prime}$ and $E_{W L}^{\prime}$ in Equations (11) and (14), have a linear relationship with $p$ only if $\Delta H^{\prime}$ is null. Thus, the hypothesis of Mamade et al. [21] is valid under the no energy loss condition. Both $E_{l}^{\prime}$ and $E_{W L}^{\prime}$ depend on $\Delta H^{\prime}$ in Equation (9b). The value of $\Delta H^{\prime}$ should be between 0 and 1 . If the head loss $(\Delta H)$ is sufficiently smaller than the input head $(H), \Delta H^{\prime}$ will be close to 0 . As a result, $E_{l}^{\prime}$ is slightly smaller than $p$, while $E_{W L}^{\prime}$ is slightly larger than $p$. On the other hand, if $\Delta H$ is comparable to $H, \Delta H^{\prime}$ will approach unity, and the discrepancies between $E_{l}^{\prime}, E_{W L}^{\prime}$ and $p$ grow with an increase in $\Delta H^{\prime}$. Figure 3 shows $p_{n}$ as a function of $p$ from Equation (15) for $n=1,1.852$ and 2. If $n=1$, it implies a laminar flow, and the curve is a negative parabola with the maximum $p_{n}$ of 0.25 at $p=0.5$ and the minimum $p_{n}$ of 0 at $p=0$ and 1 . For the case of complete turbulence, rough pipes $(n=2)$, the curve is skewed to the right with the maximum $p_{n}$ of around 0.385 at $p \approx 0.423$. For the Hazen-Williams formula $(n=1.852)$, the curve differs from the $n=2$ curve slightly. Thus, $E_{W L}^{\prime}$ approaches $p$ when $p$ is very low or extremely high, and the maximum deviation of $E_{W L}^{\prime}$ from $p$ occurs when the percentage of water loss is around $40 \%-50 \%$. In this study, $n$ is assumed to be 2 for simplicity. 


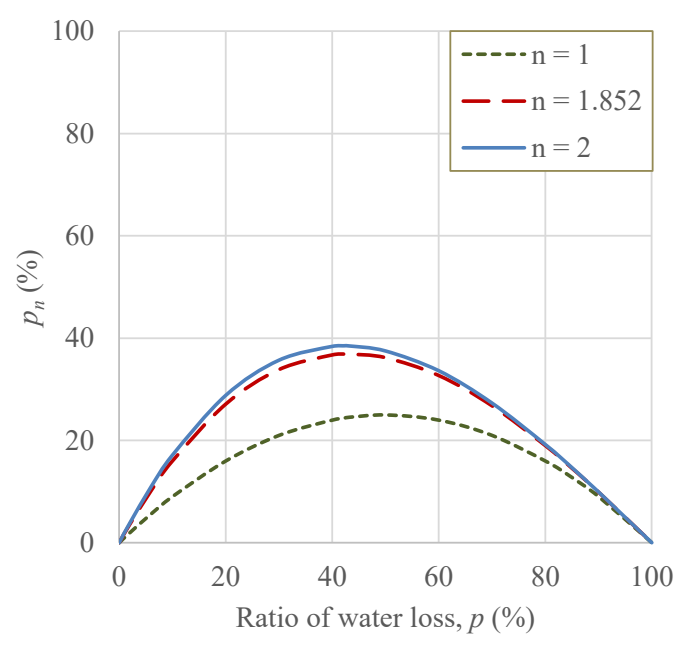

Figure 3. Relationship between parameter $p_{n}$ and ratio of water loss, $p$.

\subsection{Branched Pipe Network with Uniformly Distributed Demand Nodes}

The effects of branching and demand distribution on energy balance are investigated theoretically in this section. Here, the second network is introduced. It consists of branched pipes, and each branched pipe has uniformly distributed demand nodes as shown in Figure 4. A parameter $m$ denotes the number of branches, and $j$ denotes the number of demand nodes in each branch. Each branch has the same hydraulic properties, where the demand nodes have the same outflow of $Q / \mathrm{m} / j$ and they distribute uniformly along the branch. In addition, the constant friction slope along each branch is assumed, and the head loss equals $K(Q / m)^{n}$ at the end of each branch. These assumptions are used to simplify the problem and to make it possible to be solved theoretically. They will be discussed in the later section using the results from the real network models.

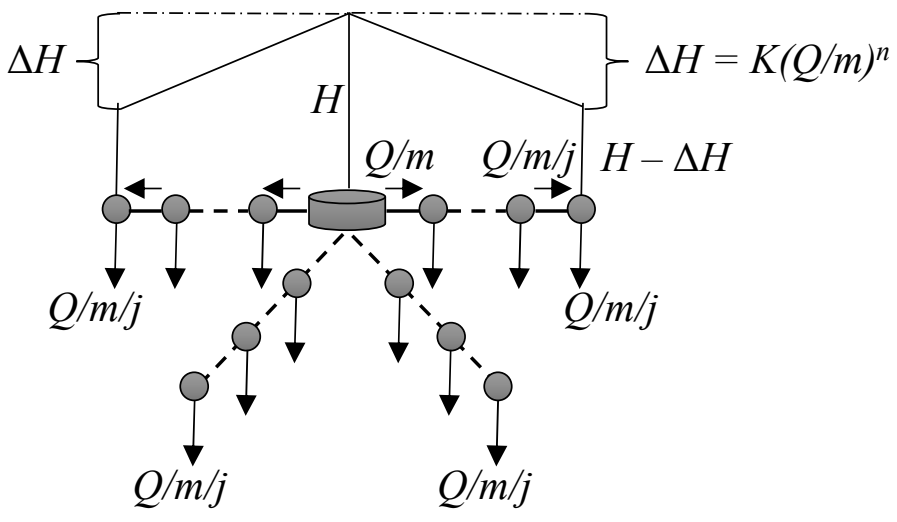

Figure 4. Energy balance for simplified branched pipe network with uniformly distributed demand nodes, where $m$ is number of branches and $j$ is number of demand nodes in each branch.

For the network in Figure 4, the energy balance components can be calculated as follows.

1. Input energy $\left(E_{i n}\right)$

$$
E_{\text {in }}=\gamma Q H
$$

2. Outgoing energy through water loss $\left(E_{l}\right)$

$$
E_{l}=m \sum_{i=1}^{j} \gamma \frac{Q_{l i}}{m}\left[H-\frac{i}{j} K\left(\frac{Q}{m}\right)^{n}\right]=\gamma Q_{l}\left[H-\left(\frac{1}{2 m^{n}}\right)\left(1+\frac{1}{j}\right) K Q^{n}\right]
$$


3. Friction energy loss $\left(E_{f}\right)$

$$
E_{f}=m \sum_{i=1}^{j} \gamma \frac{Q_{i}}{m} \frac{K\left(\frac{Q}{m}\right)^{n}}{j}=\left(1+\frac{1}{j}\right) \frac{\gamma Q\left(K Q^{n}\right)}{2 m^{n}}
$$

4. Friction energy loss for a water loss-free network $\left(E_{f_{0}}\right)$

$$
E_{f o}=\left(1+\frac{1}{j}\right) \frac{\gamma Q_{u}\left(K Q_{u}^{n}\right)}{2 m^{n}}
$$

5. $\quad$ Energy associated with water loss $\left(E_{W L}\right)$

$$
E_{W L}=E_{l}+E_{f}-E_{f o}
$$

Using the nondimensionalization in Equation $(9 a, b)$ the normalized energy balance components can be written as

1. Normalized input energy $\left(E_{i n}^{\prime}\right)$

$$
E_{\text {in }}^{\prime}=1
$$

2. Normalized outgoing energy through water loss $\left(E_{l}^{\prime}\right)$

$$
E_{l}^{\prime}=p-C_{m j} p \Delta H^{\prime}
$$

3. Normalized friction energy loss $\left(E_{f}^{\prime}\right)$

$$
E_{f}^{\prime}=C_{m j} \Delta H^{\prime}
$$

4. Normalized friction energy loss for a water loss-free network $\left(E_{f_{0}}^{\prime}\right)$

$$
E_{f o}^{\prime}=C_{m j}(1-p)^{n+1} \Delta H^{\prime}
$$

5. Normalized energy associated with water loss $\left(E_{W L}^{\prime}\right)$

$$
E_{W L}^{\prime}=p+C_{m j} p_{n} \Delta H^{\prime}
$$

where

$$
C_{m j}=\left(\frac{1}{2 m^{n}}\right)\left(1+\frac{1}{j}\right)
$$

The normalized energy balance components in Equations (22)-(25) of the second case are the generalized versions of the results from the first case in Equations (11)-(14), respectively, considering the effects of branching and demand distribution on the energy balance. The parameter $C_{m j}$ in Equation (26) is a multiplier in the $\Delta H^{\prime}$ term and has a value between 0 and 1 . For the network with one branch $(m=1)$ and one demand node $(j=1)$, $C_{m j}$ equals to 1 and the components in Equations (22)-(25) are simplified into Equations (11)-(14), respectively. An increase in branches $(m>1)$ and demand nodes $(j>1)$ produces a smaller value of $C_{m j}$ and subsequently, an increase in $E_{l}^{\prime}$ but a decrease in $E_{f}^{\prime}, E_{f_{o}}^{\prime}$ and $E_{W L}^{\prime}$. Thus, $C_{m j}$ is the coefficient representing different water distribution patterns. Since $C_{m j}$ in Equation (26) is derived theoretically under many assumptions, we are going to find appropriate values of $C_{m j}$ for each energy balance component using the results of our network models later. 


\subsection{Utilization of Theory to Real Networks}

The estimations of three normalized energy balance components, $E_{l}^{\prime}, E_{f}^{\prime}$ and $E_{W L^{\prime}}^{\prime}$ for real networks are discussed here. Up to this point, our theoretical analysis considers the energy balance of a single time period. To apply the theory to a real application, the extended period analysis is performed to evaluate the time-averaged values of $E_{l}^{\prime}, E_{f}^{\prime}$ and $E_{W L}^{\prime}$. However, the time-averaged $\Delta H^{\prime}$ terms may be too complicated for a top-down approach. Thus, for simplicity, we proposed the following theoretical estimations for real networks.

$$
\begin{gathered}
E_{l, \text { theo }}^{\prime}=\bar{p}-C_{m j} \overline{p \Delta H^{\prime}} \cong p-C_{m j} p \Delta H^{*} \\
E_{f, \text { theo }}^{\prime}=C_{m j} \overline{\Delta H^{\prime}} \cong C_{m j} \Delta H^{*} \\
E_{W L, \text { theo }}^{\prime}=\bar{p}+C_{m j} \overline{p_{n} \Delta H^{\prime}} \cong p+C_{m j} p_{n} \Delta H^{*}
\end{gathered}
$$

where the subscript theo denotes the theoretical estimation, the bar ${ }^{-}$expresses time average and $\Delta H^{*}$ is the renormalized head loss, written as

$$
\Delta H^{*}=\frac{\bar{H}_{\max }-\bar{H}_{\min }}{\bar{H}_{\max }}
$$

where $\bar{H}_{\max }$ is the maximum time-averaged energy head and $\bar{H}_{\min }$ is the minimum timeaveraged energy head. The source with the maximum head can be chosen as the $\bar{H}_{\max }$ point, and the location where the maximum head loss occurs is the $\bar{H}_{\min }$ point. Thus, the $\bar{H}_{\text {min }}$ location depends on network topology as well as demand distribution. The highest possibility is the furthest dead end from the source.

\section{Application to Real Water Networks}

\subsection{Characteristics of Water Networks}

In this section, 20 real water networks (Table 1) are used to test our theoretical analysis of energy balance. They are real district metering areas (DMAs) in the service area of the Samut Prakan branch office of the Metropolitan Waterworks Authority (MWA), Thailand. Samut Prakan is a province located at the mouth of the Chao Phraya River. Thus, the elevations refer to mean sea level (MSL). While the first 10 DMAs have 1 inlet (district meter), the remaining 10 DMAs have 2 inlets. The number of customers ranges from 739 to 11,545 connections with an average of 3508 connections. The average length and distribution pipe diameter are $40.8 \mathrm{~km}$ and $159 \mathrm{~mm}$, respectively. While the average friction slope $\left(S_{f}\right)$ from our network models ranges from $0.07 \mathrm{~m} / \mathrm{km}$ to $0.70 \mathrm{~m} / \mathrm{km}$ with an average of $0.23 \mathrm{~m} / \mathrm{km}, S_{f}$ from the study of Mamade et al. [21] ranges from $0.1 \mathrm{~m} / \mathrm{km}$ to $1.2 \mathrm{~m} / \mathrm{km}$ with an average of $0.19 \mathrm{~m} / \mathrm{km}$. Based on the average value, the networks in our study have larger values of $S_{f}$. Mamade et al. [21] explained that their networks are overdesigned; thus, the impact on head loss by adding water loss is small. This implies that the estimation of the normalized energy associated with water loss $\left(E_{W L}^{\prime}\right)$ is not sensitive to head loss in their study. However, using our theory, $E_{W L, t h e o}^{\prime}$ in Equation (29) is a function of the normalized water loss $(p)$ and head loss $\left(\Delta H^{*}\right)$, not $S_{f}$. Our case study covers values of $p$ between $2.8 \%$ and $54.9 \%$, and values of $\Delta H^{*}$ between $7.6 \%$ and $65.3 \%$. Thus, the impact of head loss on the estimation of energy balance components can be investigated in our study. 
Table 1. Characteristics of district metering areas.

\begin{tabular}{|c|c|c|c|c|c|c|c|}
\hline \multirow{2}{*}{ ID } & \multirow{2}{*}{$\begin{array}{l}\text { No. of } \\
\text { Inlets }\end{array}$} & \multirow{2}{*}{$\begin{array}{c}\text { No. of } \\
\text { Customers }\end{array}$} & Length & Avg. $D$ & Avg. $S_{f}$ & Water Loss, $p$ & $\Delta H^{*}$ \\
\hline & & & $(\mathbf{k m})$ & $(\mathrm{mm})$ & $(\mathrm{m} / \mathrm{km})$ & $(\%)$ & $(\%)$ \\
\hline 1 & 1 & 2669 & 24.5 & 161 & 0.17 & 37.1 & 16.6 \\
\hline 2 & 1 & 2657 & 26.4 & 147 & 0.17 & 28.6 & 35.7 \\
\hline 3 & 1 & 4399 & 52.3 & 148 & 0.08 & 44.6 & 14.1 \\
\hline 4 & 1 & 2626 & 46.4 & 174 & 0.20 & 38.5 & 44.2 \\
\hline 5 & 1 & 3594 & 54.7 & 139 & 0.11 & 44.2 & 18.4 \\
\hline 6 & 1 & 4812 & 51.0 & 143 & 0.36 & 54.9 & 40.7 \\
\hline 7 & 1 & 4607 & 43.2 & 130 & 0.17 & 32.4 & 44.8 \\
\hline 8 & 1 & 1695 & 28.8 & 208 & 0.09 & 12.9 & 13.7 \\
\hline 9 & 1 & 3634 & 18.1 & 183 & 0.16 & 29.7 & 14.4 \\
\hline 10 & 1 & 1820 & 22.5 & 132 & 0.14 & 2.8 & 14.8 \\
\hline 11 & 2 & 1921 & 22.2 & 166 & 0.50 & 30.0 & 35.0 \\
\hline 12 & 2 & 2151 & 19.0 & 154 & 0.16 & 50.9 & 7.6 \\
\hline 13 & 2 & 2297 & 24.9 & 154 & 0.22 & 31.9 & 25.9 \\
\hline 14 & 2 & 739 & 17.3 & 191 & 0.33 & 33.9 & 32.0 \\
\hline 15 & 2 & 1468 & 15.9 & 178 & 0.70 & 7.7 & 34.8 \\
\hline 16 & 2 & 4204 & 47.4 & 153 & 0.48 & 36.3 & 37.0 \\
\hline 17 & 2 & 11,545 & 129.6 & 150 & 0.14 & 30.7 & 45.3 \\
\hline 18 & 2 & 4460 & 73.7 & 180 & 0.15 & 30.0 & 65.3 \\
\hline 19 & 2 & 4957 & 51.5 & 143 & 0.07 & 31.2 & 18.4 \\
\hline 20 & 2 & 3897 & 47.4 & 154 & 0.28 & 47.2 & 27.8 \\
\hline Avg. & 1.5 & 3508 & 40.8 & 159 & 0.23 & 32.8 & 29.3 \\
\hline
\end{tabular}

Our pipe networks are modeled using the EPANET version 2.00.12.01 software (United States Environmental Protection Agency (US EPA), Columbus, OH, USA) [29]. Each customer is connected to distribution pipes by creating imaginary valves with no friction loss (not considering the friction loss on the service connection). Water loss is assumed to be pressure-dependent and simulated using the emitter function in the EPANET software. The emitter coefficients are distributed to all nodes of the networks. These extended period simulation (EPS) models are calibrated and provided by MWA and simulated on the average of the hourly base using the flow and pressure measurements and monthly water sales in March 2019. Thus, the models provide high levels of detail and accuracy. As examples, Figure 5 shows four DMAs (ID1, ID2, ID11 and ID13) used in this study, where the water distribution patterns of our networks vary from branching to semi-gridiron. 


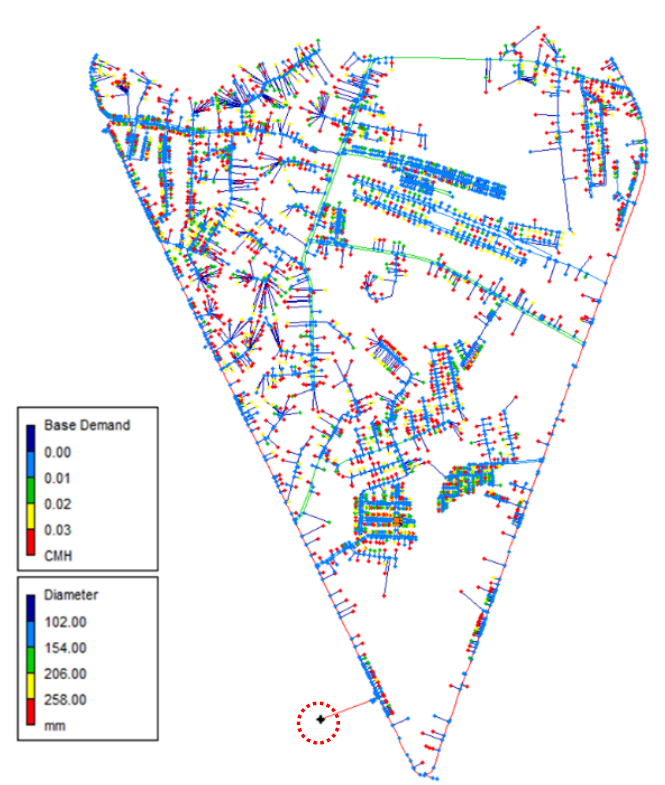

(a) ID1 with 1 inlet
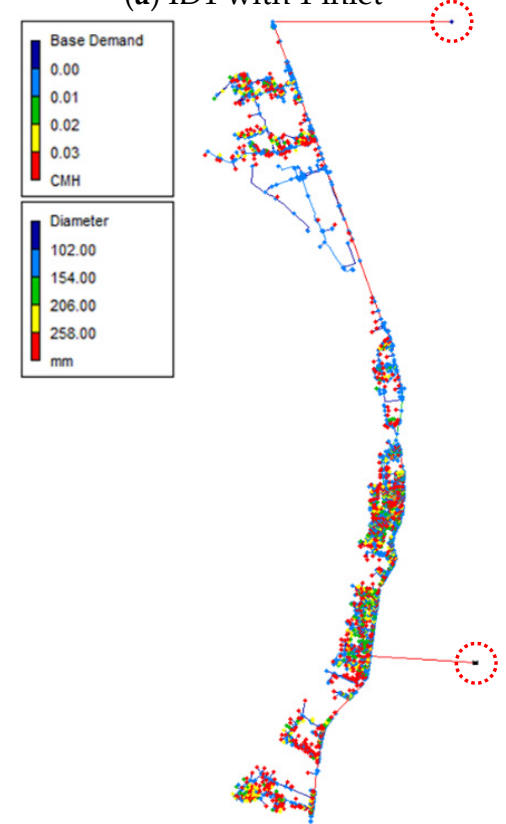

(c) ID11 with 2 inlets

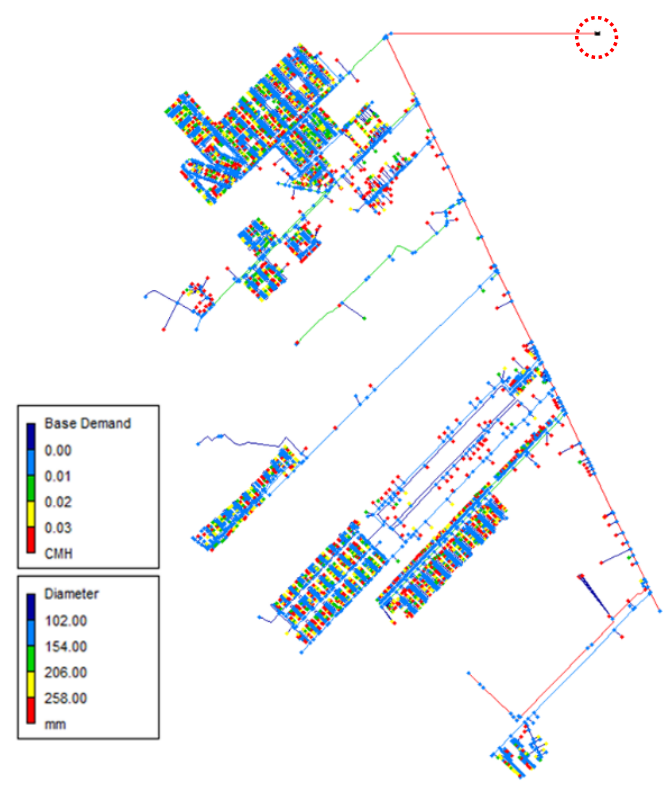

(b) ID2 with 1 inlet

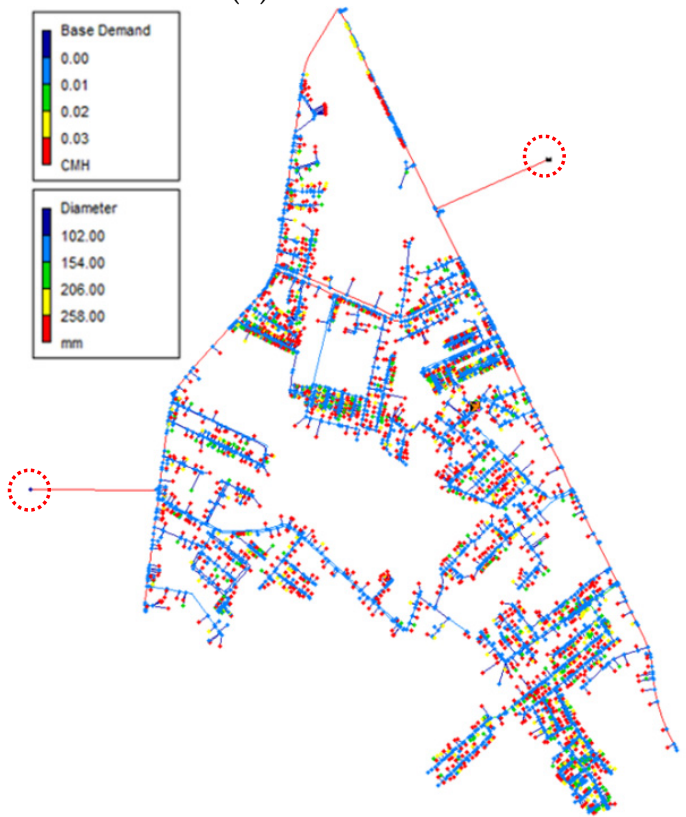

(d) ID13 with 2 inlets

Figure 5. Examples of water networks, where (a,b) are networks with 1 inlet, and (c,d) are networks with 2 inlets. Red dashed circles show the inlets connecting to the networks by imaginary valves with no friction loss.

\subsection{Basic Relationship for Energy Balance Components}

The energy balance components extracted from the simulation results using EPANET (United States Environmental Protection Agency (US EPA), Columbus, OH, USA) models of 20 water networks are compared with the basic network parameters $\left(p\right.$ and $\left.\Delta H^{*}\right)$ in Figure 6 . The normalized outgoing energy through water loss by the models $\left(E_{l, \text { mod }}^{\prime}\right)$ shows a good relationship with $p$ (Figure 6a). The values of $E_{l, m o d}^{\prime}$ are slightly to moderately smaller than $p$. This tendency corresponds with the estimation of $E_{l, t h e o}^{\prime}$ in Equation (27) by our theoretical analysis, showing that $E_{l, \text { theo }}^{\prime}$ is smaller than $p$ due to the second term that relates to $\Delta H^{*}$. Figure $6 \mathrm{~b}$ shows a good relationship between the normalized friction energy loss by the models ( $E_{f, \text { mod }}^{\prime}$ ) and $\Delta H^{*}$. While $E_{f, \text { mod }}^{\prime}$ for 1 inlet is comparable to $\Delta H^{*}, E_{f, \text { mod }}^{\prime}$ for 2 inlets seems to be smaller than $\Delta H^{*}$. According to Equation (28), $E_{f, \text { theo }}^{\prime}$ 
depends on only $\Delta H^{*}$ with $C_{m j}$ as the slope. We hypothesize that the number of inlets affects the value of $C_{m j}$. Thus, the calibration process of $C_{m j}$ in the next section will divide into two groups as 1 inlet and 2 inlets. In Figure $6 c$, the normalized energy loss associated with water loss by the models $\left(E_{W L, m o d}^{\prime}\right)$ shows a good relationship with $p$, similar to the case of $E_{l, \text { mod }}^{\prime}$ in Figure 6a. However, the values of $E_{W L, m o d}^{\prime}$ are slightly to moderately larger than $p$. The result agrees with the theoretical $E_{W L, t h e o}^{\prime}$ in Equation (29) that $E_{W L \text {,theo }}^{\prime}$ is higher than $p$ because of the additional friction energy due to an increased flow by water loss. The effect increases as $\Delta H^{*}$ increases.

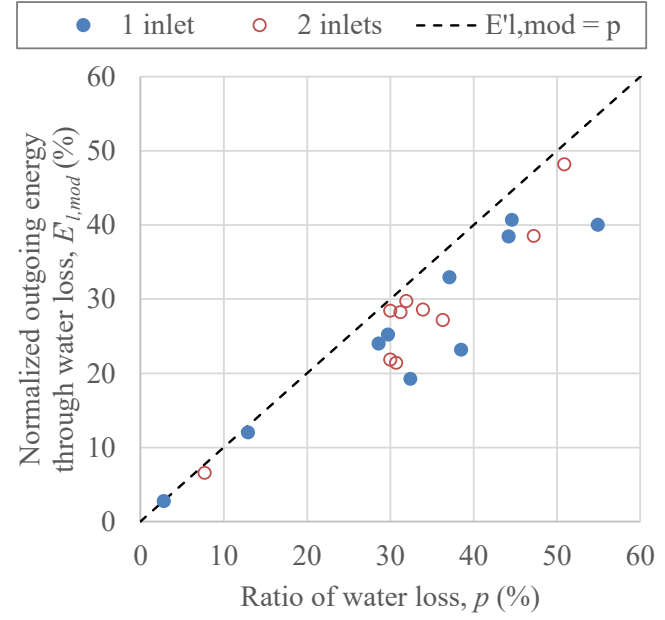

(a)

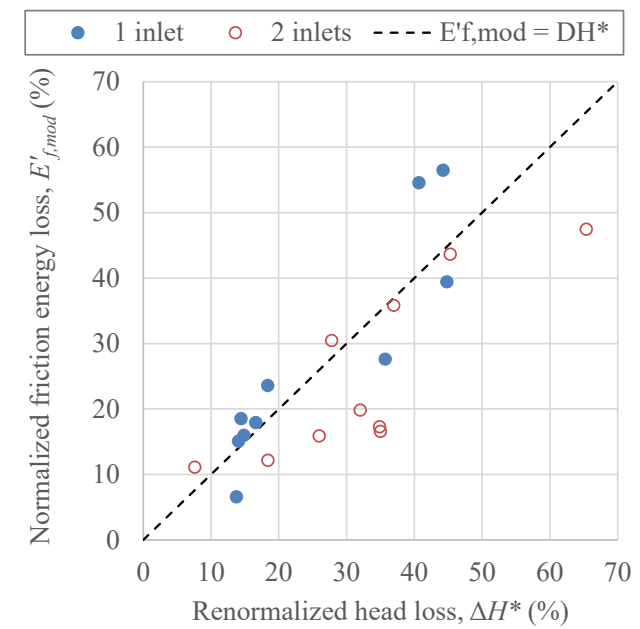

(b)

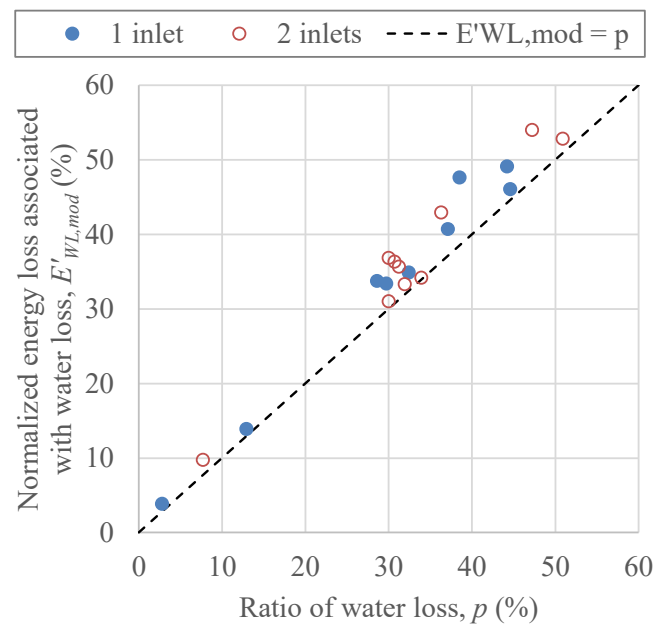

(c)

Figure 6. Relationships between energy balance components calculated by EPANET models and basic network parameters, where (a) $E_{l, \text { mod }}^{\prime}$ vs. $p$, (b) $E_{f, \text { mod }}^{\prime}$ vs. $\Delta H^{\prime}$ and (c) $E_{W L, \text { mod }}^{\prime}$ vs. $p$.

\section{Estimation of Energy Balance Components}

In this section, the theoretical estimations of the energy balance components ( $E_{l, t h e o}^{\prime}$ ' $E_{f, \text { theo }}^{\prime}$ and $E_{W L, t h e o}^{\prime}$ in Equations (27)-(29)) are compared with the model results. Using the method of least squares, the values of the coefficient $C_{m j}$ are evaluated separately for each energy balance component and the number of inlets. Figure 7 shows the comparisons between the three energy balance components using the EPANET models and the theoretical estimations. Table 2 shows the values of the calibrated $C_{m j}$ used for Figure 7 . In the table, "Before" means the basic relationship case that $E_{l}^{\prime}$ and $E_{W L}^{\prime}$ are estimated to be $p$ and $E_{f}^{\prime}$ equals to $\Delta H^{*}$. This case corresponds to the results in Figure 6. "After" refers to the 
theoretical estimations after considering the calibrated $C_{m j}$ in Figure 7. The correlation $(r)$ and the root mean square error (RMSE) for the "Before" and "After" cases are evaluated. The agreements improve substantially as the terms of $\Delta H^{*}$ with the calibrated $C_{m j}$ are considered. $E_{l}^{\prime}$ and $E_{W L}^{\prime}$ can be estimated accurately as their RMSEs are around $2 \%$. It is possible to estimate $E_{f}^{\prime}$ roughly as its RMSE is around 7\%. An increase in the number of inlets from 1 to 2 causes a decrease in $C_{m j}$, implying that the effects of branching and demand distribution become stronger. Although a number of assumptions have been used, the statistical evaluation in Table 2 shows a good performance of our theory over a wide range of $p$ and $\Delta H^{*}$. Thus, our theoretical method can be used as an effective tool to estimate the energy balance components as a top-down energy balance approach.

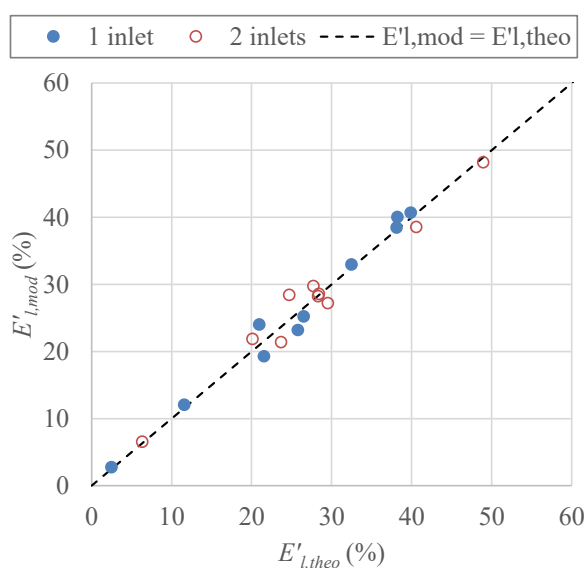

(a)

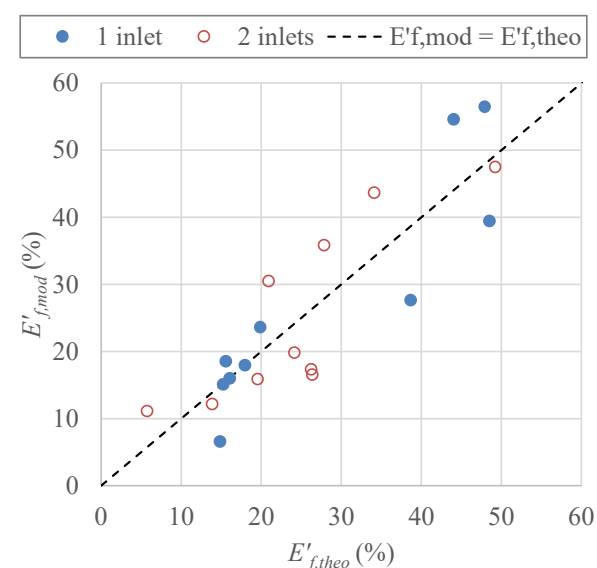

(b)

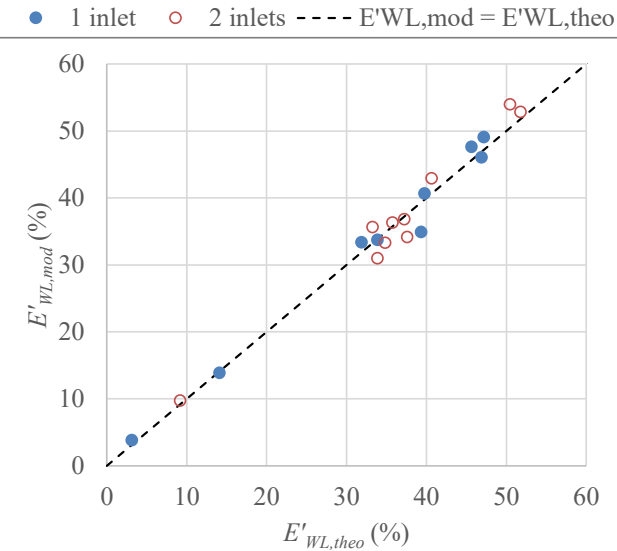

(c)

Figure 7. Comparison between energy balance components calculated by EPANET models and ones estimated by theory, where (a) $E_{l, \text { mod }}^{\prime}$ vs. $E_{l, \text { theo }}^{\prime}(\mathbf{b}) E_{f, \text { mod }}^{\prime}$ vs. $E_{f, \text { theo }}^{\prime}$ and (c) $E_{W L, \text { mod }}^{\prime}$ vs. $E_{W L, t h e o}^{\prime}$.

Table 2. Performance of proposed theoretical methods to evaluate energy balance components before and after considering normalized head loss $\Delta H^{\prime}$ with calibrated coefficient $C_{m j}$.

\begin{tabular}{|c|c|c|c|c|c|c|c|}
\hline \multirow{2}{*}{ Component } & \multirow{2}{*}{ Equation } & \multirow{2}{*}{ No. of Inlets } & \multirow{2}{*}{ Value of $C_{m j}$} & \multicolumn{2}{|c|}{$r$} & \multicolumn{2}{|c|}{ RMSE (\%) } \\
\hline & & & & Before & After & Before & After \\
\hline \multirow[t]{2}{*}{$E_{l}^{\prime}$} & $(27)$ & 1 & 0.7466 & 0.939 & 0.990 & 8.57 & 1.65 \\
\hline & & 2 & 0.5047 & 0.957 & 0.985 & 6.02 & 1.91 \\
\hline \multirow[t]{2}{*}{$E_{f}^{\prime}$} & $(28)$ & 1 & 1.0833 & 0.905 & 0.905 & 7.32 & 6.92 \\
\hline & & 2 & 0.7538 & 0.834 & 0.834 & 11.30 & 6.99 \\
\hline \multirow[t]{2}{*}{$E_{W L}^{\prime}$} & (29) & 1 & 0.4219 & 0.992 & 0.994 & 4.75 & 1.83 \\
\hline & & 2 & 0.3095 & 0.978 & 0.984 & 4.46 & 2.17 \\
\hline
\end{tabular}


Figure 8 shows the boxplots of the distribution of water demand in the network subarea corresponding to the head loss distribution. We cluster demand nodes of the network into 10 subareas according to the ratio of the head loss in each subarea to the total head loss $\left(\Delta H_{i} / \Delta H\right)$ as $0.1,0.2, \ldots, 1$. For example, the subarea of $\Delta H_{i} / \Delta H=0.1$ means the subarea covering the demand nodes having head loss between $0 \%-10 \%$ of the total head loss, and the subarea of $\Delta H_{i} / \Delta H=0.2$ means the one with head loss between $10 \%-20 \%$ of the total head loss. Then, the water demands including water loss of all nodes in each subarea are summarized and normalized by the total water demand $\left(Q_{i} / Q_{i n}\right)$. In our theory, the uniform distribution of water demand is assumed; thus, $Q_{i} / Q_{i n}$ must be constant. Under this assumption, $Q_{i} / Q_{i n}$ should equal to 0.1 for every subarea in this example. However, for the networks with 1 inlet in Figure 8a, more $Q_{i} / Q_{i n}$ is distributed in the subareas with higher $\Delta H_{i} / \Delta H$, implying that larger water demand is located further from the source in the energy sense. This nonuniform distribution of the demand amplifies the effect of head loss on the energy balance components. For the networks with 2 inlets, $Q_{i} / Q_{i n}$ is distributed in the subareas with smaller $\Delta H_{i} / \Delta H$ to a greater extent than for the case of 1 inlet. Thus, the effect of head loss on the energy balance components is less, as the values of $C_{m j}$ for 2 inlets are smaller than the ones for 1 inlet in Table 2.

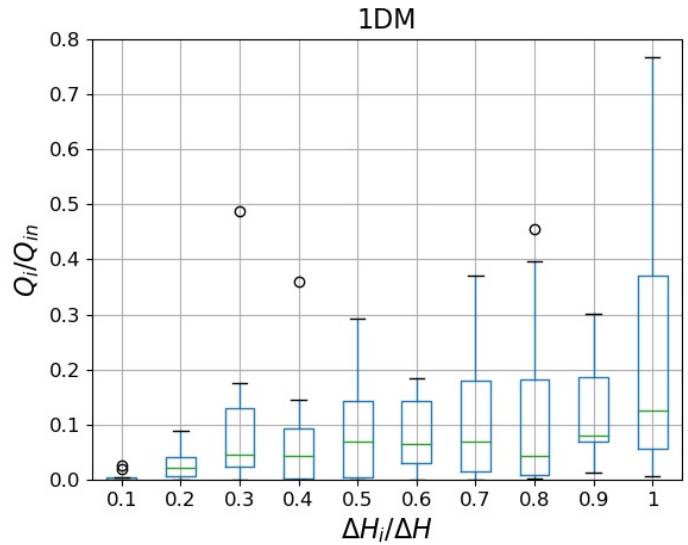

(a)

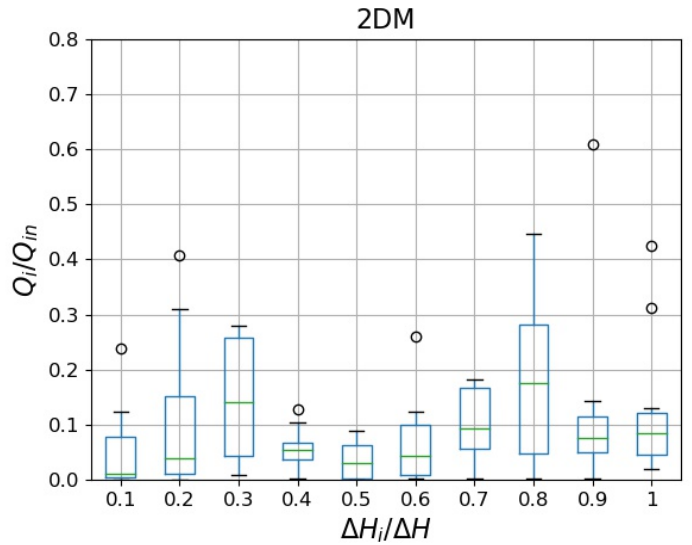

(b)

Figure 8. Boxplots of normalized demand distribution $\left(Q_{i} / Q_{i n}\right)$ vs. normalized head loss distribution $\left(\Delta H_{i} / \Delta H\right)$, where $(\mathbf{a})$ is for networks with 1 inlet and (b) is for networks with 2 inlets. Circles show the outliers.

\section{Conclusions}

To perform the energy audit based on physical processes without mathematical modelling (top-down approach), the normalized energy loss associated with water loss by the input energy $\left(E_{W L}^{\prime}\right)$ was simply assumed to equal the water loss ratio $(p)$ as in previous studies [19-21]. Using the theoretical analysis of energy balance, the renormalized head loss by the input head $\left(\Delta H^{*}\right)$ was another important parameter to estimate $E_{W L}^{\prime}$ accurately. For a practical application, $\Delta H^{*}$ can be calculated by measuring maximum and minimum energy heads in a network. In addition, the normalized outgoing energy through water loss $\left(E_{l}^{\prime}\right)$ and the normalized friction energy loss $\left(E_{f}^{\prime}\right)$ were first derived theoretically. These energy components are fundamental and crucial for an accurate energy assessment. The effects of demand distribution in the networks with 1 and 2 inlets on the estimation of energy balance components showed that the greater number of inlets caused less head loss effects on the energy balance components. These effects can be evaluated effectively through the coefficient $C_{m j}$ in our theory.

Author Contributions: Conceptualization, S.L. and A.P.; methodology, A.P.; software, S.L., S.K., N.C., J.C. and A.P.; validation, S.L., S.K. and A.P.; formal analysis and investigation, S.K., N.C. and A.P.; writing—original draft preparation, A.P.; writing—review and editing, S.L., J.C. and A.P.; 
visualization, N.C. and A.P.; supervision, S.L., J.C. and A.P.; funding acquisition, A.P. All authors have read and agreed to the published version of the manuscript.

Funding: This research was funded by the MWA Waterworks Institute of Thailand (MWAIT), grant number $109 / 2561$. S.K. was supported by the Ph.D. scholarship by the Faculty of Engineering, Kasetsart University, grant number 61/01/WE/D.ENG.

Institutional Review Board Statement: Not applicable.

Informed Consent Statement: Not applicable.

Data Availability Statement: Data was provided from Metropolitan Waterworks Authority, Thailand (MWA). Direct requests for these materials may be made to the provider, as indicated in the acknowledgments.

Acknowledgments: The authors would like to thank three anonymous reviewers for their constructive reviews that helped to improve the manuscript greatly. In addition, the authors gratefully acknowledge Metropolitan Waterworks Authority (MWA) for providing data sets using in this study.

Conflicts of Interest: The authors declare no conflict of interest.

\section{Abbreviations}

The following symbols are used in this paper:

DMA district metering area

IWA International Water Association

MWA Metropolitan Waterworks Authority, Thailand

$C_{m j} \quad$ parameter in Equation (26)

$D \quad$ pipe diameter

$E_{A C} \quad$ energy associated with authorized consumption

$E_{f} \quad$ friction energy loss

$E_{f}^{\prime} \quad$ normalized friction energy loss

$E_{f, \text { mod }}^{\prime} \quad$ normalized friction energy loss evaluated by mathematical model

$E_{f, \text { theo }}^{\prime}$

$E_{f o}$ normalized friction energy loss estimated by theory

friction energy loss for a water loss-free network

$E_{f o}^{\prime}$

$E_{\text {in }}$

$E_{\text {in }}^{\prime}$

$E_{l}$

$E_{l}^{\prime}$

$E_{l, \bmod }^{\prime}$

$E_{l, \text { theo }}^{\prime}$ normalized friction energy loss for a water loss-free network

input energy normalized input energy

outgoing energy through water loss normalized outgoing energy through water loss

normalized outgoing energy through water loss by mathematical model normalized outgoing energy through water loss by theory

$E_{W L} \quad$ energy associated with water loss

$E_{W L}^{\prime}$

$E_{W L, \bmod }^{\prime}$ normalized energy associated with water loss normalized energy associated with water loss by mathematical model normalized energy associated with water loss by theory input energy head number of demand nodes in each branch loss coefficient number of branches flow exponent in head loss formula ratio of water loss coefficient as a function of $p$ inflow flow in subarea $i$ flow due to water loss flow to supply authorized consumption friction slope system input volume

$\begin{array}{ll}\text { SIV } & \text { system input } \\ W L & \text { water loss }\end{array}$

$\gamma \quad$ specific gravity 
$\Delta H \quad$ head loss between the source and the minimum energy point

$\Delta H^{\prime} \quad$ normalized head loss between the source and the minimum energy point

$\Delta H^{*} \quad$ renormalized head loss in Equation (30)

$\Delta H_{i} \quad$ head loss in subarea $i$

\section{References}

1. International Energy Agency (IEA). Water Energy Nexus-Excerpt from the World Energy Outlook 2016; World Energy Outlook; IEA: Paris, France, 2016; p. 60.

2. Loureiro, D.; Silva, C.; Cardoso, M.A.; Mamade, A.; Alegre, H.; Rosa, M.J. The Development of a Framework for Assessing the Energy Efficiency in Urban Water Systems and Its Demonstration in the Portuguese Water Sector. Water 2020, 12, 134. [CrossRef]

3. Vilanova, M.R.N.; Balestieri, J.A.P. Exploring the water-energy nexus in Brazil: The electricity use for water supply. Energy 2015, 85, 415-432. [CrossRef]

4. Pelli, T.; Hitz, H. Energy indicators and savings in water supply. J. Am. Water Work. Assoc. 2000, 92, 55-62. [CrossRef]

5. World Bank. A Primer on Energy Efficiency for Municipal Water and Wastewater Utilities; Technical Report; 001.12. 2012b; ESMAP: Washington, DC, USA, 2012.

6. WWAP. The United Nations World Water Development Report 2014: Water and Energy; UNESCO: Paris, France, 2014 ; Volume 1.

7. Colombo, A.F.; Karney, B.W. Energy and Costs of Leaky Pipes: Toward Comprehensive Picture. J. Water Resour. Plan. Manag. 2002, 128, 441-450. [CrossRef]

8. Colombo, A.F.; Karney, B.W. Impacts of Leaks on Energy Consumption in Pumped Systems with Storage. J. Water Resour. Plan. Manag. 2005, 131, 146-155. [CrossRef]

9. Bylka, J.; Mroz, T. A Review of Energy Assessment Methodology for Water Supply Systems. Energies 2019, 12, 4599. [CrossRef]

10. Cabrera, E.; Pardo, M.A.; Cobacho, R. Energy Audit of Water Networks. J. Water Resour. Plan. Manag. 2010, $136,669-677$. [CrossRef]

11. Cabrera, E.; Cobacho, R.; Soriano, J. Towards an Energy Labelling of Pressurized Water Networks. Procedia Eng. 2014, 70, 209-217. [CrossRef]

12. Cabrera, E.; Gomez, E.; Cabrera, E., Jr.; Soriano, J. Calculating the Economic Level of Friction in Pressurized Water Systems. Water 2018, 10, 763. [CrossRef]

13. Cabrera, E.; Gómez, E.; Soriano, J.; Del Teso, R. Eco-Layouts in Water Distribution Systems. J. Water Resour. Plan. Manag. 2019, 145, 04018088. [CrossRef]

14. Cabrera, E.; Gomez, E.; Soriano, J.; Espert, V. Energy Assessment of Pressurized Water Systems. J. Water Resour. Plan. Manag. 2015, 141, 04014095. [CrossRef]

15. Gomez, E.; Cabrera, E.; Balaguer, M.; Soriano, J. Direct and Indirect Water Supply: An Energy Assessment. Procedia Eng. 2015, 119, 1088-1097. [CrossRef]

16. Hashemi, S.; Filion, Y.R.; Speight, V.L. Pipe-level Energy Metrics for Energy Assessment in Water Distribution Networks. Procedia Eng. 2015, 119, 139-147. [CrossRef]

17. Sarbu, I. A Study of Energy Optimisation of Urban Water Distribution Systems Using Potential Elements. Water 2016, 8, 593. [CrossRef]

18. Gómez, E.; Del Teso, R.; Cabrera, E.; Cabrera, J.E.; Soriano, J. Labeling Water Transport Efficiencies. Water 2018, 10, 935. [CrossRef]

19. Mamade, A.; Sousa, C.; Marques, A.; Loureiro, D.; Alegre, H.; Covas, D. Energy Auditing as a Tool for Outlining Major Inefficiencies: Results from a Real Water Supply System. Procedia Eng. 2015, 119, 1098-1108. [CrossRef]

20. Mamade, A.; Loureiro, D.; Alegre, H.; Covas, D. A comprehensive and well tested energy balance for water supply systems. Urban Water J. 2017, 14, 853-861. [CrossRef]

21. Mamade, A.; Loureiro, D.; Alegre, H.; Covas, D. Top-Down and Bottom-Up Approaches for Water-Energy Balance in Portuguese Supply Systems. Water 2018, 10, 577. [CrossRef]

22. Cabrera, E.; Del Teso, R.; Gómez, E.; Cabrera, E.; Estruch-Juan, E. Deterministic Model to Estimate the Energy Requirements of Pressurized Water Transport Systems. Water 2021, 13, 345. [CrossRef]

23. Lenzi, C.; Bragalli, C.; Bolognesi, A.; Artina, S. From energy balance to energy efficiency indicators including water losses. Water Supply 2013, 13, 889-895. [CrossRef]

24. Dziedzic, R.; Karney, B.W. Energy Metrics for Water Distribution System Assessment: Case Study of the Toronto Network. J. Water Resour. Plan. Manag. 2015, 141, 04015032. [CrossRef]

25. Wong, H.G.; Speight, V.L.; Filion, Y.R.; Wong, H.G. Impact of Urban Development on Energy Use in a Distribution System. J. Am. Water Work. Assoc. 2017, 109, E10-E18. [CrossRef]

26. Lapprasert, S.; Pornprommin, A.; Lipiwattanakarn, S.; Chittaladakorn, S. Energy Balance of a Trunk Main Network in Bangkok, Thailand. J. Am. Water Work. Assoc. 2018, 110, E18-E27. [CrossRef]

27. Lipiwattanakarn, S.; Kaewsang, S.; Pornprommin, A.; Wongwiset, T. Real benefits of leak repair and increasing the number of inlets to energy. Water Pract. Technol. 2019, 14, 714-725. [CrossRef]

28. Alegre, H.; Baptista, J.M.; Cabrera, E.; Cubillo, F.; Duarte, P.; Hirner, W.; Merkel, W.; Parena, R. Performance Indicators for Water Supply Services; IWA Publishing: London, UK, 2006.

29. Rossman, L.A. EPANET 2 Users Manual, Water Supply and Water Resources Division; USEPA: Cincinnati, OH, USA, 2000. 